\title{
Determinants of Accident Occurrence among Commercial Motor Cycle Riders in Kaloleni Sub-County, Kilifi County, Kenya
}

\author{
Baya Mkaha Zuma1.2*, Shadrack Ayieko Yonge², Joseph Baya Msanzu³, Rahma Udu \\ Yussuf ${ }^{3}$
}

${ }^{1}$ Coast General Teaching and Referral Hospital, Mombasa County

P.O. Box 90231 - 80100 Mombasa, Kenya; ${ }^{2}$ Department of Environment and Health Sciences, Technical University of Mombasa, P.O. Box 90420 - 80100 Mombasa, Kenya; ${ }^{3}$ Department of Pure and Applied Sciences, Technical University of Mombasa, P.O. Box 90420-80100 Mombasa

Kenya

*Corresponding author's email: bayazuma@yahoo.co.ke

\begin{abstract}
$\mathrm{M}$ otorcycle accidents remain one of the main global concerns despite extensive research and interventions. The African region has the highest road fatality rates globally, in spite of being the least motorized region. Kenya has an estimated road fatality rate of 20.9 per 100,000 people, higher than that of the European region. There has been an increased use of motorcycles in Kenya over the last decade, so has the number of deaths from motorcycle injury. This study was aimed to establish the determinants of accident occurrence among commercial motorcycle riders in Kaloleni sub-County, Kilifi County, Kenya. A self- administered structured questionnaire was used to collect data from 279 commercial motorcycle riders. Factors associated with accident occurrence were analysed using both bivariate and multivariate analysis. Results showed that $29.2 \%$ of the respondents had been involved in a road traffic accident in the past 12 months by the time of the study. Factors that were independently associated with motorcycle accidents included riding experience of more than 8 years $(p=0.040)$, alcohol use $(p=0.040)$, slippery roads $(p=0.020)$ and pot holes on roads $(p=<0.001)$. Moreover, participants acquired their riding skills from friends $(64.9 \%)$ or self-trained $(33.6 \%)$. It can be concluded that motorcycle accidents is still a major public health problem in the study area due to the recorded high rate. Thus, it is recommended that all motorcyclists should be well trained and issued with riding license after attending formal training, and strict penalties imposed against anybody contravening road traffic rules. Moreover, roads should be continuously improved to reduce accident rates.
\end{abstract}

Key Words: Commercial motor cycles, Accident occurrence, Determinants, Kilifi County, Kenya

\section{Introduction}

The increase in the use of motorcycles as a form of road transport for commercial or public transport in Africa is a relatively recent phenomenon. Road transport plays an important role in integrating the various sectors in any given economy in the world. This is because the transport sector makes crucial contribution to overall economic growth and development (Berg et al., 2017; Gumel et al., 2017). Thus, based on the concept of sustainable development of society, transport has a significant importance for the balanced development of socio- economic systems of a country (Nistor \& Popa, 2014).

In urban areas, the inability of transport systems to meet the demand for urban commuters has led to the acceptance of motorcycles in many of the cities of Africa as an alternative means of transport to solve the commuting problems. Due to the transport system's inability to fully meet the commuters' transportation needs and the availability of motorcycles, the demand for this mode of transport has been on an upward trend (Kumar \& Barret, 2008). 
Public transport is still developing in Kenya and motorcycle transportation has greatly helped in filling the gap in the transport system. In the last five years, motorcycles have flooded the Kenyan roads, both in cities and villages (Chepchieng', 2011; KNBS, 2016). This is partly due to the zero rating of all motorcycles below 250cc in 2008 (Nyachieo, 2015). The zero rating of duty levied on imported motorcycles was meant to create employment for the young people (Nyachieo, 2013). It is projected that commercial motorcycle services growth will continue increasing globally because majority of the population needs a flexible means of transport (Nyachieo, 2015). Majority of the motorcycles-taxi business users and operators are mainly from the poor Kenyan population (Starkey, 2016).

Motorcycles play a crucial role in the Kenyan transport sector today. They are an alternative mode of transport especially for the low and middle income earners. Where motorcycle taxis exist, they provide huge social and economic benefits in rural areas (Nyachieo, 2013). On many rural roads they are the only means of motorized transport available to most rural people (Starkey, 2016). They serve as taxis and provide the convenience of travelling irrespective of time, type of road, distance or destination, in addition to being readily available. Motorcycles taxis can be found on nearly any street corner and can drop customers off at their exact location. In Kenya, boda boda motorcycles can be traced back to when boda boda bicycles were used for cross border trade between Kenya and Uganda in Busia County (Howe, 2003).

The rapid growth of motorcycle transport has come with its own share of challenges. Motorcycles pose a wide range of challenges especially in the developing countries (Ndwiga et al., 2019). The higher rate of motorization increases road traffic accidents (RTAs) (Islam \& Al Hadhrami, 2012; Matheka et al., 2015; Muguro et al., 2020). The growth in usage of motorized two- or threewheeled vehicles has been reported to increase injuries and fatalities among users (Soehodho, 2017; Olvera et al., 2019; Wang et al., 2019). RTAs and the associated injuries are the main cause of death and disability globally, are the eighth leading cause of death for all ages and account for 1.35 million deaths annually (WHO, 2015).
Majority of these deaths occur in developing countries (Manyara, 2016). Kenya as a country, ranked as a lower middle-income, has experienced an increase in RTAs over the last decade (Muguro et al., 2020).

In Kenya, over 3,000 people die through road accidents every year, most of them in their prime ages (Manyara, 2016). A total of 3,114 road traffic deaths were reported by the National Transport and Safety Authority (NTSA) in the year 2020 (NTSA, 2020); of these, approximately $7 \%$ were motor cyclists (WHO, 2011). Additionally, between 2015 and 2016 the deaths related to motorcycles accidents increased by 3\%, from $21 \%$ in 2015 to $24 \%$ in 2016 (Kibogong, 2017).

Among commonly cited risk factors for motorcycle crashes include excessive speed, alcohol and drug abuse, road and weather conditions, inexperience and unlicensed riding (Lin \& Krauss, 2009; Chung et al., 2014; Slesak et al., 2015; Xiong et al., 2016). The thriving boda boda sub-sector has also been blamed for increasing road traffic accidents as a result of impunity and violation of laws (Opondo \& Kiprop, 2018). Boda boda accidents are frequent owing to risky riding behaviours such as riding while under the influence of alcohol and drugs, poor maintenance of motorcycles and low levels of professional training (Nyachieo, 2015; Nguyen et al., 2018). Boda boda traffic accident related deaths and injuries have become major public health epidemics in Kenya (Nyameino, 2018).

Deaths from boda boda related accidents have negative impacts on the economy (Gathecha et al., 2018). In addition to the serious and debilitating injuries suffered, there are huge medical bills and financial costs to the riders, pillion passengers, pedestrians and other motorists involved in such accidents (Opondo \& Kiprop, 2018). In addition, for those injured in accidents, the treatment is long and expensive because most of them sustain head and limb injuries, not to mention the emotional pain for relatives in the case of death. Studies estimating the financial implications of road traffic injuries of a country ranges between $1.3 \%$ and 3.0\% of gross domestic product (GDP) (Manyara, 2016). If nothing is done about the increasing motorcycle accidents, the percentage is envisaged to increase. The rate at which accidents are occurring on daily 
basis on our roads does not justify the large amount of money being paid to various agencies in charge of road safety in Kenya.

Concerted efforts are needed to combat this menace. Road traffic injuries and fatalities involving motorcycles riders are an extremely overlooked problem in Kenya and can be better studied and hopefully prevented. As a result, this study intended to examine the root cause of the incessant occurrences of accidents, especially among commercial motorcycle riders in Kaloleni Sub-County in Kilifi County, Kenya. It is believed that if known, it will help a great deal to implement measures that will reduce the high rates of the accidents occurrence among commercial motorcycle riders in Kaloleni Sub-County and Kenya at large.

\section{Materials and Methods}

\section{Study Area}

The study was conducted in Kaloleni sub-County, Kilifi County, West of the Mombasa City. Kaloleni Sub-County was purposely chosen because of the existence of the very busy traffic lanes; the NairobiMombasa highway, a passageway for all types of vehicles to and from Mombasa City (personal cars, passenger vehicles, as well as light and heavy trucks). Kaloleni sub-County has two constituencies, namely Kaloleni with a population of 139,302 and Rabai with a population of 113,622 (KNBS, 2019). The sub-county has a strong industrial sector with the Mabati Rolling Mills and the Athi River Cement Factory contributing heavily to the region's economy, both in employment provision and income generation. The ethnic communities living in these areas are Giriama, Rabai, Kambe, Gibana, Ribe and a mixture of people from other communities.

\section{Study Design}

A cross-sectional descriptive study design was employed. The design was efficient in determining the predictors of accidents among commercial motorcycle riders during that particular period.

\section{Study Population}

The target populations for this study were all the 1,023 registered commercial motorcycle riders residing in Kaloleni sub-County (KNBS, 2019). All consenting commercial motorcycle riders residing in Kaloleni sub-County were recruited while nonconsenting commercial motorcycle riders and those who did not reside in Kaloleni sub-County were excluded.

\section{Sample Size Determination}

The study sample was determined by using the Cochran (1977) formula:

$$
\mathrm{n}=\frac{z^{2} p q}{d^{2}}
$$

Where:

$\mathrm{n}$ = sample size for a population;

$\mathrm{z}=\mathrm{z}$-value corresponding to a $95 \%$ level of significance $=1.96$;

$\mathrm{p}=$ expected proportion of motorcycle riders in Kaloleni sub-County $(\mathrm{p}=0.5)$;

$q=(1-p)=(1-0.5)=0.5$, and

$\mathrm{d}=$ absolute precision, set at $5 \%$.

The sample size obtained was 384 but was adjusted using the formula by Saunders et al. (2009) to obtain a final sample estimate (nf);

$$
\mathrm{n}_{\mathrm{f}}=\frac{n}{1+\frac{n}{N}}
$$

Where:

$\mathrm{nf}=$ the desired sample size (when the population is $<10,000$ );

$\mathrm{n}=$ the desired sample size (when the population is $>10,000)$, and

$\mathrm{N}=$ total targeted population in the study area $(1,023)$.

Therefore, the final sample size was 279 motorcycle riders.

\section{Sampling Procedure}

The registered motorcycle riders were dived into seven clusters based on their areas of operation. Proportionate to size sampling was used in the seven clusters identified with the total registered motorcycle riders as follows: Mariakani with a population of 370 had a sub-sample of 101, Kibanda-hasara with a population of 47 had a subsample of 13 riders, Uwanja-wa-ndege with a population of 33 had a sub-sample of 9 riders, Kokotoni with a population of 47 had a sub-sample of 13 riders, Mazeras with a population of $175 \mathrm{had}$ 
a sub-sample of 48 riders, Rabai Centre with a population of 108 had a sub-sample of 29 riders, and Kaloleni township with a population of 243 had a sub-sample of 66 riders. Individual riders within each cluster were then chosen randomly.

\section{Data Collection Techniques}

Structured questionnaires were used to gather quantitative data relevant to the objectives of this study from a total of 279 motorcycle riders. The questionnaire was translated into Kiswahili which is a common language and then back-translated into English to ensure accuracy in the wording of the questions. The questionnaire was then revised to remove problems in interpretation and language comprehension. An observation checklist was also used; all observations were recorded immediately in the check list to avoid recall bias. Data was collected between January and March 2019.

\section{Ethical Consideration}

Approval to conduct the study was obtained from Technical University of Mombasa Ethical Review Committee. The local authorities and County Health Officers were informed of the study activities and their approval secured. Confidentiality and privacy was observed in data collection and handling. Informed consent was sought from research participants before inclusion into the study; those not willing to participate were excluded.

\section{Data Management and Analysis}

The questionnaire was coded and the data was entered in EpiData (Version 3.1) database. The data was then exported to both IBM SPSS statistical software Version 24 and R for windows Version 3.6.2 for data checking, cleaning, and analysis. Descriptive statistics was done. Chi-square was used to test the association between accident occurrence (dependent variable) and training and experience, drug and substance abuse, and road and weather conditions (independent variables). Further, bivariate analysis was performed to prove the hypothesis that there are critical predisposing factors that lead to accident occurrence among commercial motorcycle riders in Kaloleni subCounty, at $95 \%$ significance level.

\section{Results}

\section{Socio-demographic Characteristics of the Respondents}

All the respondents who were recruited for this study were male (100\%), with majority of them aged 18 and 25 years old. Slightly more than half of the participants $(57.6 \%)$ belonged to Islamic religion. Majority of the participants were educated through to secondary school $(63.1 \%)$, were not married $(58.7 \%)$ and earned a daily income of USD 3-5 (59.8\%) (Table 1).

Moreover, most of the motor cyclists recruited in this study were licenced $(84.1 \%)$ by the relevant authority (NTSA), with only $15.9 \%$ not possessing riding licences. However, majority had been trained by friends $(64.9 \%)$ or self-trained $(33.6 \%)$. Majority $(68.3 \%)$ had been riding the motor cycle for a period of between 1and 4 years but majority $(72 \%)$ of these riders were not the sole owners of these motor cycles, rather they were employed (Table 2). 
Table 1: Socio-demographic characteristics of motor cycle riders in Kaloleni sub-County, March 2019

\begin{tabular}{lll}
\hline Characteristic & $\begin{array}{l}\text { Frequency } \\
\text { (n=271) }\end{array}$ & $\begin{array}{l}\text { Percentage } \\
\text { (\%) }\end{array}$ \\
\hline Gender & & \\
Male & 271 & 100 \\
Female & 0 & 0 \\
\hline Age (in years) & 3 & \\
Below 18 & 162 & 59.8 \\
18-25 & 106 & 39.1 \\
Above 25 & & \\
\hline Religion & 115 & 42.4 \\
Christian & 156 & 57.6 \\
Muslim & & \\
\hline Educational level & 10 & 3.7 \\
No education & 57 & 21 \\
Primary & 171 & 63.1 \\
Secondary & 33 & 12.2 \\
College/University & 33 & \\
\hline Marital status & & 58.7 \\
Single & 159 & 35.8 \\
Married & 97 & 5.5 \\
Separated/Divorced & 15 & \\
\hline Amount of daily & & \\
income (in USD.) & & 59.8 \\
> 3 & 4 & 38.7 \\
Between 3-5 & 162 & \\
> 5 & 105 & \\
\hline
\end{tabular}

\section{Factors Associated with Accident Occurrence among Commercial Motorcycle Riders}

Results of Chi-square tests (Table 3) indicated statistically significant association between age and accident occurrence $\left(\chi^{2}=8.030, p=0.020\right)$. The proportion of motor cyclists who had accidents increased from $21.7 \%$ to $100 \%$ among those aged above 25 and below 18 years. However, there were no statistically significant associations between accident occurrence with religion, education level, marital status, and daily income ( $p<0.050$ in all cases). The occurrence of accident was slightly higher among Muslims (29.5\%), and increased from $15.2 \%$ among those who had college/university education to $36.8 \%$ in those with primary education. Accident occurrence was also slightly higher among participants who were married $(30.9 \%)$, and those earning a daily income of USD. 3-5 (32.7\%).
Table 2. Training and experience of motorcycle riders in Kaloleni sub-County, March 2019

\begin{tabular}{lll}
\hline Characteristic & $\begin{array}{l}\text { Frequency } \\
(\mathbf{n = 2 7 1 )}\end{array}$ & $\begin{array}{l}\text { Percentage } \\
(\mathbf{\%})\end{array}$ \\
\hline $\begin{array}{l}\text { Trainers of } \\
\text { motorcyclist }\end{array}$ & 4 & \\
$\begin{array}{l}\text { Driving school } \\
\text { From friends }\end{array}$ & 176 & 1.56 \\
Self & 91 & 4.9 \\
\hline $\begin{array}{l}\text { Possess riding } \\
\text { license }\end{array}$ & & 33.6 \\
Yes & & \\
No & 228 & 84.1 \\
\hline Years of riding & 43 & 15.9 \\
$\begin{array}{l}\text { 1-4 } \\
\text { 5-8 }\end{array}$ & 185 & 68.3 \\
Above 8 & 55 & 20.3 \\
\hline $\begin{array}{l}\text { Ownership } \\
\text { Self-employed } \\
\text { (solely own it) }\end{array}$ & 31 & 11.4 \\
Employed & 76 & \\
\hline
\end{tabular}

The same Chi-square test recorded a statistically significant association between trainer of the motor cyclist and accident occurrence $\chi^{2}=$ $10.550, p=0.010)$. Occurrence of accident was slightly higher among the commercial motor cyclists who acquired their riding skills by themselves $(41.8 \%)$ and those who were unlicensed (34.9\%), compared to those who were licensed (28.1\%). However, there was no statistically significant association between training source and motor cycle accident.

With regard to riding experience, a statistically significant association $\left(\chi^{2}=7.760, p=0.020\right)$ with accident occurrence was also registered. The occurrence of accidents was higher among those who had been riding for a period of between 1 and 4 years $(32.5 \%)$. Motor cyclists who were employed (31.3\%) as riders had also caused more 
accidents compared to those who solely owned their motorbikes $(23.7 \%)$ but there was no statistically significant association between motor cycle ownership and motor cycle accident $(\mathrm{p}<0.05)$.

Table 3. Results of Chi-square test for association between socio-demographic characteristics of participants and accidents occurrence in Kaloleni sub- County, March 2019. *Statistically significant $(p<0.05)$

\begin{tabular}{|c|c|c|c|}
\hline \multirow[t]{2}{*}{ Characteristic } & \multicolumn{2}{|c|}{ Accident occurrence in past 12 months } & \multirow[b]{2}{*}{$\begin{array}{l}\text { Chi-square }\left(\chi^{2}\right), \\
\text { p-value }\end{array}$} \\
\hline & $\begin{array}{l}\text { Yes } \\
\text { n (\%) }\end{array}$ & $\begin{array}{l}\text { No } \\
\text { n }(\%)\end{array}$ & \\
\hline Gender & & & - \\
\hline Male & $79(29.2)$ & $192(70.8)$ & \\
\hline Female & 0 & 0 & \\
\hline Age (in years) & & & $X^{2} \mathrm{R} 8.03$ \\
\hline Below 18 & $3(100.0)$ & $0119(73.5)$ & $\mathrm{p}=0.020^{*}$ \\
\hline $18-25$ & $43(26.5)$ & $73(68.9)$ & \\
\hline$>25$ & $33(31.1)$ & & \\
\hline Religion & & & $x^{2}=4.21 \mathrm{e}^{-05}$ \\
\hline Christian & $33(28.7)$ & $82(71.3)$ & $p=0.990$ \\
\hline Muslim & $46(29.5)$ & $110(70.5)$ & \\
\hline Educational level & & & $x^{2}=4.770$ \\
\hline No education & $3(30.0)$ & $7(70.0)$ & $\mathrm{p}=0.190$ \\
\hline Primary & $21(36.8)$ & $36(63.2)$ & \\
\hline Secondary & $50(29.2)$ & $121(70.8)$ & \\
\hline College/University & $5(15.2)$ & $28(84.8)$ & \\
\hline Marital status & & & $x^{2}=0.760$ \\
\hline Single & $46(28.9)$ & $113(71.1)$ & $p=0.680$ \\
\hline Married & $30(30.9)$ & $67(69.1)$ & \\
\hline Separated/Divorced & $3(20.0)$ & $12(80.0)$ & \\
\hline Trainers of motor cyclist & & & $x^{2}=10.550$ \\
\hline Driving school & $1(25.0)$ & $3(75.0)$ & $\mathrm{p}=0.010^{*}$ \\
\hline From friends & $40(22.7)$ & $136(77.3)$ & \\
\hline Self & $38(41.8)$ & $53(58.2)$ & \\
\hline Possess riding license & & & $x^{2}=0.520$ \\
\hline Yes & $64(28.1)$ & 164(71.9) & $p=0.470$ \\
\hline No & $15(34.9)$ & $28(65.1)$ & \\
\hline Years of riding & & & $x^{2}=7.760$ \\
\hline $1-4$ & $62(32.5)$ & $123(66.5)$ & $\mathrm{p}=0.020^{*}$ \\
\hline $5-8$ & $14(25.5)$ & $41(74.5)$ & \\
\hline$>8$ & $3(9.7)$ & $28(90.3)$ & \\
\hline Ownership & & & $x^{2}=1.180$ \\
\hline Self-employed & $18(23.7)$ & $58(76.3)$ & $\mathrm{p}=0.280$ \\
\hline Employed & $61(31.3)$ & $134(68.7)$ & \\
\hline
\end{tabular}




\section{Independent Predictors of Accident Occurrence among Commercial Motor Cyclists}

Results of multivariate logistic regression analysis on independent predictors and accident occurrence varied (Table 4). Respondents who were below 18 years were 5.25 times more likely to be involved in accident $(p=0.990)$ while those above 25 years of age were 1.71 times more likely to be involved in accident $(\mathrm{p}=0.220)$. Commercial motor cyclists who acquired their riding skills through self-training were 2.15 times $(p=0.960)$ more likely to be involved in an accident compared to those who acquired their riding skills through attending riding/driving schools. On the other hand, commercial motor cyclist who acquired their riding skills through friends had a reduced odd of $52 \%(p=0.650)$ of getting involved in an accident compared to those who acquired their riding skills through attending riding/driving schools.

Commercial motor cycle riders who had a riding experience of between 5 and 8 years and those with above 8 years had a reduced odd of $54 \%$ (p $=0.140)$ and $79 \%(p=0.040)$, respectively of getting involved in an accident compared to those who had riding experience of between 1 and 4 years.

Commercial motorcycle riders who consumed alcohol were 2.54 times $(p=0.040)$ more likely to be involved in accident as compared to their counterparts who were non-alcoholic. Similarly, commercial motorcycles who smoked marijuana were 1.74 times $(p=0.190)$ more likely to be involved in accident as compared to their colleagues who smoked cigarettes. Moreover, those who consumed cigarettes, marijuana and moguka (a type of khat) and palm wine after working hours had a reduced odd of $20 \%$ ( $p=$ 0.780 ) of being involved in accident as compared to their colleagues who consumed these cigarettes, marijuana and moguka and palm wine during work hours. Commercial motor cycle riders who rode on slippery roads or those with pot holes were also more likely to be involved in accidents leading to body injuries and death. 
Table 4. Results of regression analysis for independent predictors association with motorcycle accident occurrence in Kaloleni sub- County, March 2019. *Statistically significant $(\mathrm{p}<0.05)$

\begin{tabular}{|c|c|c|c|}
\hline Predictor characteristic & COR (95\% CI) & AOR (95\% CI) & p-value \\
\hline \multicolumn{4}{|l|}{ Age (in years) } \\
\hline$<18$ & $1.590 \times 10^{7}$ & $5.250 \times 10^{7}$ & 0.990 \\
\hline $18-25$ & 1.000 & 1.000 & - \\
\hline$>25$ & $1.250(0.73-2.14)$ & $1.710(0.73-4.05)$ & 0.220 \\
\hline \multicolumn{4}{|l|}{ Trainers of motorcyclist } \\
\hline Driving school & 1.000 & 1.000 & - \\
\hline From friends & $0.880(0.11-18.10)$ & $0.480(0.02-17.2)$ & 0.650 \\
\hline Self & $0.910(0.04-33.87)$ & $2.150(0.26-44.39)$ & 0.960 \\
\hline \multicolumn{4}{|l|}{ Years of riding } \\
\hline $1-4$ & 1.000 & 1.000 & - \\
\hline $5-8$ & $0.680(0.33-1.31)$ & $0.460(0.16-1.26)$ & 0.140 \\
\hline$>8$ & $0.210(0.05-0.63)$ & $0.210(0.04-0.83)$ & $0.040^{*}$ \\
\hline \multicolumn{4}{|l|}{ Alcohol use } \\
\hline Yes & $2.710(1.45-5.06)$ & $2.540(1.04-6.27)$ & $0.040^{*}$ \\
\hline No & 1.000 & 1.000 & - \\
\hline \multicolumn{4}{|l|}{ Drugs/substances taken } \\
\hline Cigarettes & 1.000 & 1.000 & - \\
\hline Miraa/muguka & $0.610(0.21-1.70)$ & $0.670(0.16-2.66)$ & 0.580 \\
\hline Cigarettes \& miraa/muguka & $1.330(0.53-3.41)$ & $0.970(0.30-3.16)$ & 0.960 \\
\hline Marijuana/Bhang & $6.560(0.42-117.22)$ & $1.750(0.36-8.69)$ & 0.190 \\
\hline None & $2.280(0.18-30.38)$ & $0.530(0.24-1.20)$ & 0.520 \\
\hline \multicolumn{4}{|l|}{$\begin{array}{l}\text { Time of consuming } \\
\text { drugs/substances }\end{array}$} \\
\hline During work time & $0.420(0.15-1.15)$ & $0.800(0.16-4.01)$ & 0.780 \\
\hline After working time & 1.000 & 1.000 & - \\
\hline Don't consume & $0.230(0.08-0.63)$ & $0.270(0.04-1.55)$ & 0.140 \\
\hline \multicolumn{4}{|l|}{ Cause of accidents } \\
\hline Slippery roads & $0.060(0.00-0.34)$ & $0.070(0.00-0.48)$ & $0.020^{*}$ \\
\hline Pot holes & $0.180(0.09-0.35)$ & $0.160(0.07-0.33)$ & $<0.001^{*}$ \\
\hline Slippery roads \& pot holes & $0.330(0.09-1.06)$ & $0.280(0.06-1.04)$ & 0.070 \\
\hline Over speeding & Ref & Ref & - \\
\hline Recklessness & - & - & _ \\
\hline Un-roadworthy motor cycle & $0.190(0.03-0.86)$ & $0.190(0.02-1.06)$ & 0.080 \\
\hline
\end{tabular}

\section{Discussion}

Commercial motor cycles have become a major form of public transport in most parts of Kenya. This has led to a dramatic increase in the number of registered motor cycles over the past decade. This mode of commercial transportation has introduced the riders and their passengers to risk of road accidents which is higher among this group of road users. Data by the National Transport and Safety Authority (NTSA) showed that motorcycles retained an infamous record as the highest rising cause of death on Kenyan roads despite ongoing campaigns to end this trend (NTSA, 2020). Further, the comparative statistics showed that in November 2018, some 511 motor cyclists were killed on various roads, a $17 \%$ jump compared to a similar window of the previous year.

In this study, $29.2 \%$ of the motor cycle operators in Kaloleni sub-County reported to have been involved in an accident in the previous 12 months 
by the time of this study. This current rate is slightly higher than the one reported by Ngari et al. (2020) who recorded a $24 \%$ motor cyclists' accidents in their three months of operation among the commercial motor cyclists in Embu County, Kenya. Similarly, a study conducted in Mwea Town, Kirinyaga County (Ndwiga et al., 2019) reported 38\% accident incidences. However, this is not as high as the prevalence of $68 \%$ reported in Southern Nigeria (Johnson, 2012). It is worth noting that, these accidents involving motor cycles have put a heavy burden on families, communities and the health system in general.

The current study showed that some sociodemographic characteristics influenced accident rates among motor cycle operators. Similar to the findings of Lili et al. (2016), this current study also reports dominance of male commercial motor cyclists as compared to females. The incidence of accidents was highest amongst motor cyclists of below 18 years of age and those between 18 and 25 years. Findings from other studies indicated that this is the age group at greatest risk of being involved in road traffic accidents. The only reason we can assert to the highest incidence of accident in these age groups is that, being in their late adolescence and early adulthood years, they are characterized by high speed driving, engage in risky behaviours, are always in a hurry, and aggressive (Oluwadiya et al., 2004; Owoaje et al., 2005; Nguyen, 2018).

Our study further ascertains that majority of the motor cyclists who were involved in accidents had only gone through primary school education. This group had attained just the basic education, hence, there is a possibility that they exhibit a relatively high level of ignorance, causing them not to be able to interpret road traffic regulations or signs (Zabeu et al., 2013). Occurrence of accidents was also relatively high among those who were married and earning a daily income of USD. 3-5. However, this finding was contrary to that reported by Chang \& Yeh, (2007), who observed that the correlation between road injury with being unmarried can be explained by a tendency for young people to be more risk takers, hence they are more likely to disobey traffic rules.
Further, it was observed that poor knowledge of traffic code and the desire to generate more money were significantly responsible for high rates of accidents among commercial motor cycle riders. The 2015 road safety report by the WHO indicated that wearing a good quality helmet can reduce the risk of death by $40 \%$ and the risk of serious injuries by $70 \%$ (WHO, 2015).

Findings of this current study also reveal that majority of the accidents were experienced among the riders who did not acquire any formal riding skills from the motor cycle riding schools but trained themselves or were trained by friends. This finding is in line with that of Adisa (2010) who observed that the increase in number of accidents among this group was because there was inadequate training acquired before embarking on riding expedition. Similarly, the unlicensed riders reported a higher accident occurrence; this could be explained by the fact that they were not trained on the usage of roads and the safe riding of bikes. Similar findings were reported by Lieshout (2015), who observed that often young men were the ones who were predominantly involved in the commercial motor cycle business, yet they are poorly trained and often unlicensed.

High accident rates were also observed among the riders with least riding experience of between 1 and 4 years. It was observed that inexperienced motor cyclists were more likely to take risks hence leading to accidents (Nyachieo, 2015). Our findings also showed that individuals who were employed as riders had higher accident incidences. We believe that this group was involved in reckless riding since they had a notion that after all, if the motor cycle is involved in the accident, they were not the ultimate owners and they would not incur any repair costs.

This current study sought to establish whether the road and weather conditions had any influence on accident rates among motor cycle operators in the study area. Road hazards, which may include pot holes, slippery road conditions among others were considered. Factors that were associated with accidents occurrence included bad roads, over speeding and failure to observe road signs by the riders. This finding is similar to reports 
from other developing countries which have identified bad road conditions (WHO, 2015) and excessive speeding (Ndwiga et al., 2019) as a major contributory factor to the occurrence of motor cycle accidents.

\section{Conclusion}

The study shows that age of the rider, experience of the rider, drug and alcohol use, and bad road surfaces/poor road usage account for higher percentage of the causes of motor cyclists' accidents in Kaloleni sub-County. Majority of the motor cycle riders had not attended training school. Thus, there is need to encourage motor cyclists to enrol at registered riding schools and also introduce road safety education, particularly targeted at discouraging drug and alcohol use among motor cyclists while riding. This would go a long way in reducing the occurrence of motor cycle accidents. There is also need for both the national and county governments to intensify their efforts to repair roads.

\section{Acknowledgement}

The authors of this paper would like to acknowledge the effort of those who directly or indirectly contributed to the success of this study. We also acknowledge the support of Mariakani sub-County Transport Department rendered during the field work.

\section{References}

Adisa, R.S. (2010). A study of the use of intoxicants among Rural CommercialMotorcyclists in Kwara State, Nigeria. Journal of Social Sciences, 22(2): 85 - 91

Berg, C.N., Deichmann, U., Liu, Y. \& Selod, H. (2017). Transport Policies and Development. The Journal of Development Studies, 53(4): 465-480

Chang, H.L., \& Yeh, T.H. (2007). Motorcyclist accident involvement by age, gender, and risky behaviours in Taipei, Taiwan. Transportation Research Part F: Traffic Psychology and Behaviour, 10(2): 109122

Chepchieng', J.K. (2011). The influence of urban transport policy on the growth of motorcycle and tricycles in Kenya. MA thesis University of Nairobi, Nairobi. http:/ /hdl.handle.net/11295/10124

Chung, Y., Song, T.J. \& Yoon, B.J. (2014). Injury severity in delivery-motorcycle to vehicle crashes in the Seoul metropolitan area. Accident Analysis \& Prevention, 62: 79-86

Cochran GW. Sampling Techniques. 3rd Edition. New York: John Wiley and Sons: 1977

Gathecha, G.K., Ngaruiya, C., Mwai, W., Kendagor, A., Owondo, S., Nyanjau, L., ... \& Kibachio, J. (2018). Prevalence and predictors of injuries in Kenya: Findings from the national STEPs survey. BMC public health, 18(3): 1-9

Gumel, G.B., Adam, I.M., \& Rilwan, I.A. (2017). Impact of Commercial Motorcycle Transport in Raising Income: Evidence from Jigawa State, Nigeria. CARD International Journal of Social Sciences and Conflict Management, 2(3): 74-91

Howe, J. (2003). 'Filling the middle': Uganda's appropriate transport services. Transport Reviews, 23(2): 161-176

Islam, M.M., \& Al Hadhrami, A.Y.S. (2012). Increased motorization and road traffic accidents in Oman. Journal of Emerging Trends in Economics and Management and Sciences, 3(6): 907-914

Johnson, O.E. (2012). Prevalence and pattern of road traffic accidents among commercial motorcyclists in a city in Southern Nigeria. Educational Research, 3(6): 537-542

Kibogong, D. (2017). Statistics on crashes in Kenya for road safety planning. National Transport and Safety Authority

KNBS (2016). Kenya - Small and Medium Enterprises (MSME) Survey 2016. Kenya National Bureau of Statistics. Ministry of Planning and National Development

KNBS (2019). Kenya Population and Housing Census 2019. Vol. 1: Population by County and Sub County. Kenya National Bureau of Statistics

Kumar, A., \& Barrett, F. (2008). Stuck in traffic: Urban transport in Africa. AICD Background paper, 1

Lieshout, F.M. (2015). The role of commercial motorcycles in the rural economy: A case study of Laikipia East sub-county, Kenya. Journal of Economic Literature, 2(3): 51-78

Lili, X., Yao, Z., \& Liping, L. (2016). Risk factors for motorcycle-related severe injuries in a 
medium-sized city in China. AIMS Public Health, 3 (4): 907-922

Lin, M.R., \& Kraus, J.F. (2009). A review of risk factors and patterns of motor cycle injuries. Accident Analysis \& Prevention, 41(4): 710722

Manyara, C.G. (2016). Combating road traffic accidents in Kenya: A challenge for an emerging economy. In Kenya after 50 (pp. 101-122). Palgrave Macmillan, New York.doi:https://doi.org/10.1057/9781137 574633_7

Matheka, D.M., Omar, F.A., Kipsaina, C., \& Witte, J. (2015). Road traffic injuries in Kenya: a survey of commercial motorcycle drivers. Pan African Medical Journal, 21(1): 142

Muguro, J.K., Sasaki, M., Matsushita, K. \& Njeri, W. (2020). Trend analysis and fatality causes in Kenyan roads: A review of road traffic accident data between 2015 and 2020. Cogent Engineering, 7(1):1797981. DOI: 10.1080/23311916.2020.1797981

Ndwiga, S.M., Mbakaya, C. \& Kiiyukia, C. (2019). Factors Associated with Road Traffic Accidents involving Motorcyclists in Mwea Town, Kirinyaga County, Kenya. African Journal of Health Sciences, 32(1): 74-81

Ngari, P.M., Gachohi, J., \& Ngure, K. (2020). Prevalence and factors associated with commercial motorcycle accidents in Embu County, Kenya. Journal of Health, Medicine and Nursing, 5(2): 73- 95

Nguyen, T., Vissoci, J.R.N., Joelson, T., Pesambili, M., Haglund, M., Gerardo, C.J., ... \& Staton, C.A. (2018). Injury prevalence and safety habits of boda boda drivers in Moshi, Tanzania: A mixed methods study. PLoS one, 13(11), e0207570.

Nistor, F. \& Popa, C.C. (2014). The role of transport in economic development. Naval Academy Scientific Bulletin, 17(2): 25-26

NTSA. (2020). 2020 Road Safety Status Report. National Transport and Safety Authority (NTSA). [Online]. Retrieved March 01, 2020, from. http://www.ntsa.go.ke/index.php?option $=$ com_content\&view $=$ article\&id $=237$

Nyachieo, G.M. (2015). Socio-cultural and economic determinants of boda boda motorcycle transport safety in Kisumu
County, Kenya. PhD Thesis, Kenyatta University

Nyachieo, G.M.M. (2013). Creating Employment through Transport; The Youth and Motorcycle (Boda boda) in Kitengela, Kajiado County- Kenya. Research Journal in Organizational Psychology \& Educational Studies, 2(4): 154-157

Nyameino, S., Butt, F., Guthua, S.W., Macigo, F., \& Akama, M. (2018). Occurrence and pattern of maxillofacial injuries caused by motorcycle crashes presenting at two major referral hospitals in Nairobi, Kenya. Craniomaxillofacial Trauma $\mathcal{E}$ Reconstruction Open, 2(1): s-0038

Oluwadiya, K.S., Oginni, L.M., Olasinde, A.A. \& Fadiora, S.O. (2004). Motorcycle limb injuries in a developing country. West African Journal of Medicine 23(1): 42 - 47

Olvera, D.L., Plat, D. \& Pochet, P. (2019). Looking for the obvious: Motorcycle taxi services in sub-Saharan African cities. Journal of Transport Geography, 88, 102476

Opondo, V. O., \& Kiprop, G. (2018). Boda Boda Motorcycle Transport and Security Challenges in Kenya (No. 14). National Crime Research Centre (NCRC) Research Report

Owoaje, E.T., Amoran, O.E, Osemeikhain, O. \& Ohnoferi, O.E. (2005). Incidence of road traffic accidents and pattern of injury among commercial motorcyclists in a rural community in South Western Nigeria. Journal of Community Medicine and Primary Health Care 17(1): 7-12

Saunders, M., Lewis, P., \& Thornhill, A. (2009). Research methods for business students (5th ed.): Pearson Education Limited, England

Slesak, G., Inthalath, S., Wilder-Smith, A., \& Barennes, H. (2015). Road traffic injuries in northern Laos: trends and risk factors of an underreported public health problem. Tropical Medicine $\mathcal{E}$ International Health, 20(11): 1578-1587

Soehodho, S. (2017). Public transportation development and traffic accident prevention in Indonesia. IATSS Research, 40(2): 76-80

Starkey, P. (2016). The benefits and challenges of increasing motor cycle use for rural access. In Proceedings of the International Conference on Transportation and Road Research, held on 
16 ${ }^{\text {th }}-17^{\text {th }}$ March 2016 at white Sands Hotel, Mombasa, Kenya: 15-17

Wang, D., Liu, Q., Ma, L., Zhang, Y., \& Cong, H. (2019). Road traffic accident severity analysis: A census-based study in China. Journal of Safety Research, 70: 135-147

WHO (2011). Motor cycle related road traffic crashes in Kenya facts and figures. World Health Organization

WHO (2015). Global status report on road safety 2015. World Health Organization.

Xiong, L., Zhu, Y., \& Li, L. (2016). Risk Factors for Motorcycle-related Severe Injuries in a Medium-sized City in China. AIMS public health, 3(4):907-922 https://doi.org/10.3934/publichealth.201 6.4 .907

Zabeu, J.L.A., Zovico, J.R.R., Pereira Júnior, W.N., \& Tucci Neto, P.F. (2013). Profile of motorcycle victims from the emergency service of a university hospital. Revista brasileira de ortopedia, 48(3): 242-245 